\title{
A rapid multiclass method for antibiotic residues in goat dairy products by UPLC- quadrupole/electrostatic field orbitrap high- resolution mass spectrometry
}

\author{
Lu Zhang ${ }^{1^{*}}$ (D) Liang Shi ${ }^{2}$, Qiang $\mathrm{He}^{1}$ and Ying $\mathrm{Li}^{1}$
}

\begin{abstract}
Background: Sulfanilamides, quinolones, nitroimidazoles, tetracyclines, cephalosporins, macrolides, and $\beta$-lactam are common tools in agriculture and can be found in animal-based foods such as goat milk and goat dried milk. To evaluate the risk of these species, reliable analytical methods are needed for accurate concentration determination, especially in goat milk and goat dried milk.

Method: We describe a method based on PRiME extraction coupled with UPLC-quadrupole/electrostatic field orbitrap high-resolution mass spectrometry to accomplish this task.

Result: Under optimal conditions, the limit of quantification for all antibiotics was $0.5-100 \mu \mathrm{g} / \mathrm{L}$ in goat milk and goat dried milk samples. The recoveries were $60.6-110.0 \%$ for goat milk and $60.1-109.6 \%$ for goat dried milk with a coefficient of variation less than $15 \%$. The detection limits were $0.5-1.0 \mu \mathrm{g} / \mathrm{kg}$. The limits of quantification for the analytes were $5.0-10.0 \mu \mathrm{g} / \mathrm{kg}$. Finally, the method was used to screen veterinary antibiotics in 50 local goat milk and goat dried milk samples; metronidazole and enrofloxacin were detected in goat milk.

Conclusion: This method offers good reliability and the capacity for simultaneous detection can be used to detect residual contents and evaluate health risks in goat milk and goat dried milk.
\end{abstract}

\section{Introduction}

Veterinary antibiotics are widely used to prevent infections, increase reproduction, and improve animal husbandry (Han et al. 2015; Javorska et al. 2017; Li et al. 2016; Tran et al. 2016; Reinholds et al. 2016; SerraCompte et al. 2017; Cámara et al. 2013). However, these drugs are often used in discriminately in cattle and goat feeding (Zorraquino et al. 2011), which can lead to adverse human health effects, especially for infants and children who consume large amounts of dairy products (Li et al. 2019; Li et al. 2017).

To ensure the safety of human food, several countries have established stringent food safety regulations for

\footnotetext{
*Correspondence: lindazhanglu@126.com

${ }^{1}$ Technology Centre of Xi'an Customs District P. R. China, Xi'an 710068, China Full list of author information is available at the end of the article
}

these antibiotics in animal-based foods such as eggs, milk, kidney, liver, fat, and muscle (Han et al. 2012). For example, the maximum residue limits (MRLs) of benzylpenicillin, chlortetracycline, and danofloxacinin bovine milk are $4 \mu \mathrm{g} / \mathrm{kg}, 100 \mu \mathrm{g} / \mathrm{kg}$, and $30 \mu \mathrm{g} / \mathrm{kg}$, respectively, via the European Commission (Directives2006/141/ ECand2003/89/EC). China's MRL are published (GB 31650-2019 National food safety standard-Maximum residue limits for veterinary drugs in foods 2020) and set the MRLs for benzylpenicillin, ampicillin, and moxicillin at $4 \mu \mathrm{g} / \mathrm{kg}$. Other MRLs in bovine milk include $25 \mu \mathrm{g} / \mathrm{kg}$ sulfadimidine; $30 \mu \mathrm{g} / \mathrm{kg}$ oxacillin, danofloxacin, and cloxacillin; $40 \mu \mathrm{g} / \mathrm{kg}$ erythromycin; $50 \mu \mathrm{g} / \mathrm{kg}$ flumequine, trimethoprim, tilmicosin, and sulfonamides (parent drug); 
$100 \mu \mathrm{g} / \mathrm{kg}$ sulfonamides (expect sulfadimidine), tylosin, enrofloxacin, and ceftiofur; $150 \mu \mathrm{g} / \mathrm{kg}$ lincomycinas; and $200 \mu \mathrm{g} / \mathrm{kg}$ spiramycin. These MRLs are quite low; thus, a sensitive and selective analytical method is needed.

Liquid chromatography-tandem mass spectrometry (LC-MS/MS) is a common tool in the analysis of veterinary residues. Most studies of trace antibiotic levels are based on triple quadrupole (TQ) mass spectrometry (Heller et al. 2006; Zorraquino et al. 2011; De Almeida et al. 2015; Liu et al. 2016; Li et al. 2017; Zhang et al. 2016; Forgacsova et al. 2019; Oyedeji et al. 2019; Kazakova et al. 2018; Socas-Rodríguez et al. 2017; Li et al. 2018). Multiple reaction monitoring (MRM) and selected reaction monitoring (SRM) are usually the standard quantification method. However, matrix effects and ion interference in TQ-MS remain due to complicated food composites. For better confirmation at ion and higher throughout in analysis of multi-residue veterinaries, liquid-chromatography-high resolution mass spectrometry (LC-HRMS) has become increasingly popular, specifically time-of-flight mass spectrometry (Li et al. 2016; Li et al. 2016; Berendsen et al. 2017; Zhang et al. 2015; Liu et al. 2019; Fu et al. 2018; Emhofer et al. 2019; Weng et al. 2020; Moreno-González et al. 2017; Pan et al. 2016; Saito-Shida et al. 2018) and quadrupole/electrostatic field orbitrap mass spectrometry (Jia et al. 2014b; $\mathrm{Hu}$ et al. 2019; Zhao et al. 2017; Jia et al. 2014a; Casado et al. 2018; Paepe et al. 2019; Jia et al. 2017; Casado et al. 2018; Jia et al. 2018a, 2018b; Jia et al. 2018a, 2018b; Casado et al. 2019; Rusko et al. 2019; Abdallah et al. 2019; López-García et al. 2017; Paepe et al. 2018; Kim et al. 2018; Jia et al. 2017).

Recently, new pre-treatment methods have been proposed for extraction and clean-up of each class of veterinary antibiotic residues in food samples. These include liquid-liquid extraction (LLE) for macrolides extraction from milk samples (Şanli et al. 2011) as well as a modified QuEChERS and solid-phase extraction (SPE) or dispersive SPE for clean-up of complex food samples (Junza et al. 2011; Jia et al. 2014a; Kaufmann and Widmer 2013; Dubreil-Chéneau et al. 2014; Heller et al. 2006; Chen et al. 2017). More recently, a novel phospholipids-removing SPE column-PriME HLB was developed based on the specific adsorption for phospholipids carrying fatty acid chains. In contrast to traditional SPE methods, this procedure removes interferences, fats, and phospholipids while simultaneously extracting multiple veterinary residues from milk and dried milk in one loading step; the method is convenient, fast, affordable, and green.

The objective of this study is to establish an effective method to simultaneously determine 60 selected veterinary antibiotic residues, including 17 sulfanilamides, 16 quinolones, 7 nitroimidazoles, 3 tetracyclines, 2 cephalosporins, 8 macrolides, and $7 \beta$-lactams, in milk and dried milk samples by UPLC-quadrupole/electrostatic field orbitrap high-resolution mass spectrometry. The resulting method was then successfully used to screen veterinary antibiotic residues in local goat milk and goat dried milk samples.

\section{Experimental}

\section{Chemicals and reagents}

We obtained the following from Dr. Ehrenstorfer $\mathrm{GmbH}$ (Augsburg, Germany): sulfamerazine (SMZ), sulfathiazole, trimethoprim (TMP), sulfamethizole, sulfisoxazole (SIZ), sulfadiazine (SD), sulfachlorpyridazine, sulfamethoxydiazine, sulfadimethoxypyrimidine, sulfaquinoxaline, sulfadimoxine (SDM), sulfamethoxypyridazine, sulfamethazine, sulfapyridine (SPD), sulfamethoxazole (SMX), sulfaguanidine, sulfaphenazole, lomefloxacin (LOM), ciprofloxacin (CIP), enrofloxacin (ENR), ofloxacin (OFX), norfloxacin (NOR), orbifloxacin (ORB), danofloxacin (DAN), sparfloxacin (SPA), sarafloxacin (SAR), marbofloxacin (MAR), enoxacin (ENO), flumequine (FLU), fleroxacin (FLE), difloxacin (DIF), pefloxacin (PEF), nalidixic acid, erythromycin, lincomycin (LIN), spiramycin, roxithromycin, tilmicosin (TIL), tylosin (TYL), clindamycin, kitasamycin, dimetridazole, hydroxymetronidazole, ipronidazole- $\mathrm{OH}$, ipronidazole, ornidazole, metronidazole, 2-methyl-5-nitroimidazole, chlortetracycline (CLT), doxycycline (DOX), demeclocycline (DEM), ceftiofur (TIL), cefapirin, oxacillin (OXAC), dicloxacillin (DICL), cloxacillin (CLOX), nafcillin (NAFC), ampicillin (AMPI), penicillin G (PEG), and penicillin V (PEV).

Acetonitrile and methanol were HPLC gradient grade and purchased from Merck (Darmstadt, Germany). Formic acid and acetic acid were purchased from Anpu (Shanghai, China), and doubly deionized water was obtained from a Milli-Q gradient water system (Milipore, Bedford, MA).

Stock solutions of individual compounds were prepared in methanol $\left(1000 \mathrm{mg} \mathrm{L}^{-1}\right)$ and stored at $-20{ }^{\circ} \mathrm{C}$ in dark glass bottles during the three-month validity period. The working mixed standard solution was then diluted with $0.1 \%$ formic acid solution and kept at -20 ${ }^{\circ} \mathrm{C}$ in dark glass bottles for one month. PRiME HLB solid phase extraction cartridges $(60 \mathrm{mg}, 3 \mathrm{CC})$ were obtained from Waters (Milford, USA).

\section{Sample preparation \\ Goat milk sample}

The target analytes were extracted from $1 \mathrm{~g}$ of milk sample with $4 \mathrm{~mL}$ of $0.2 \%$ formic acid/acetonitrile solution and vortexed for $30 \mathrm{~s}$. The mixture was then shaken for $30 \mathrm{~min}$ and centrifuged at $10,000 \mathrm{r} / \mathrm{min}$ for $10 \mathrm{~min}$ at 4 ${ }^{\circ} \mathrm{C}$. The total supernatant fraction was directly loaded on a PRiME HLB. All elutes were collected in a centrifugal tube and evaporated under nitrogen gas at $40{ }^{\circ} \mathrm{C}$. The 


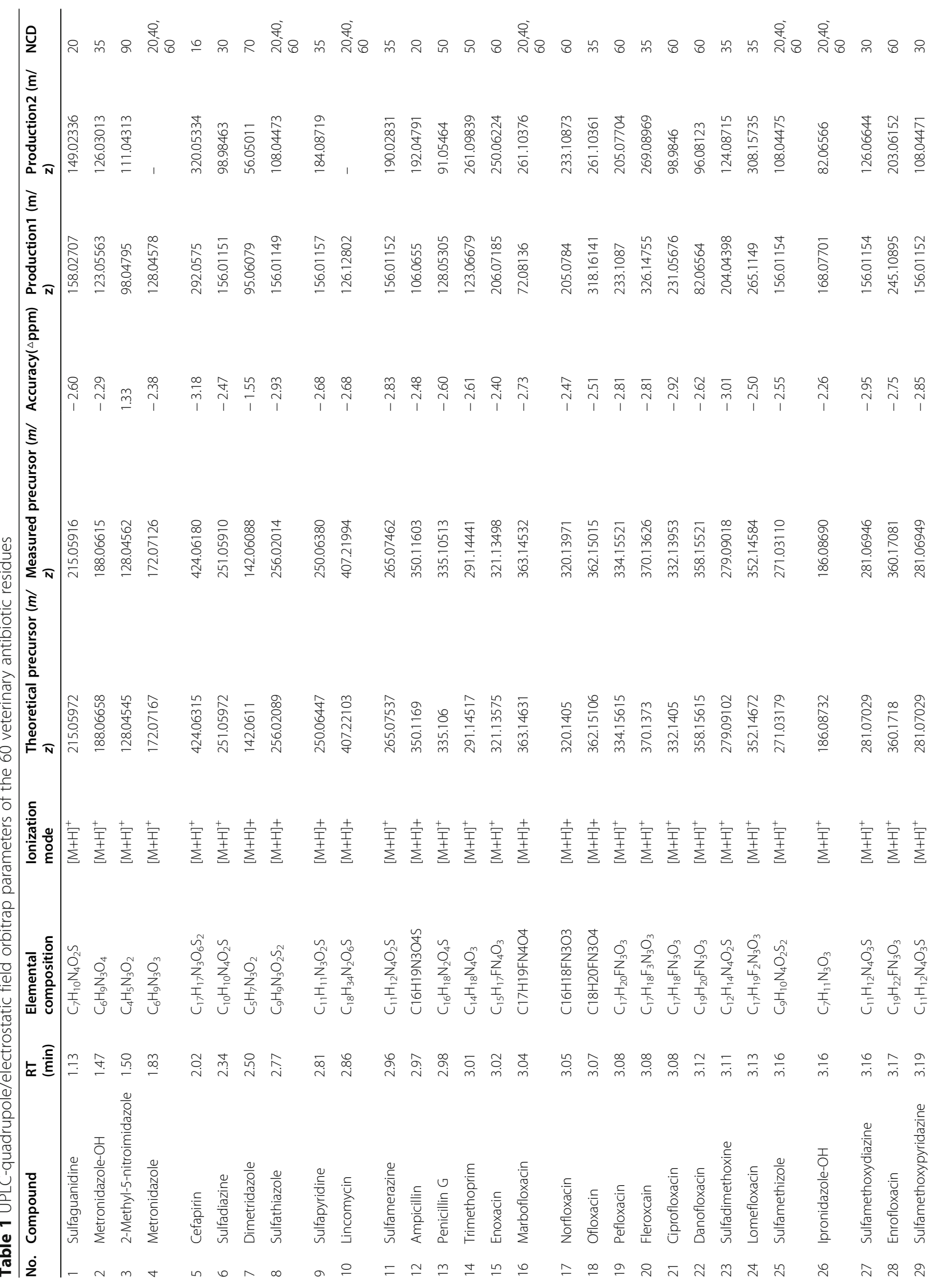




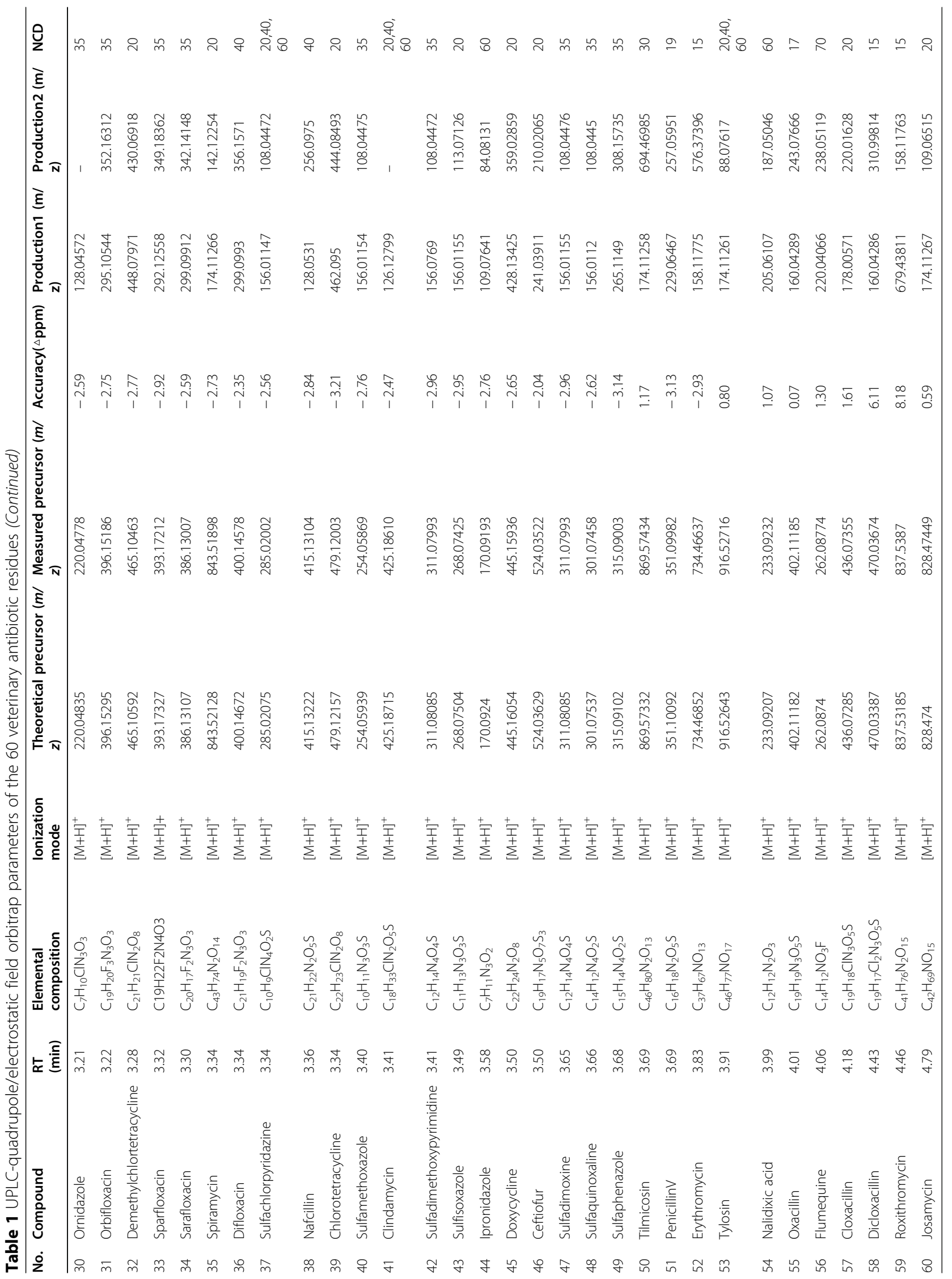


residue was added to $1 \mathrm{~mL}$ acetonitrile: $0.1 \%$ formic acid solution $(1: 9, \mathrm{v} / \mathrm{v})$ and filtered with a $0.22-\mu \mathrm{m}$ filter membrane. The final extract solution was transferred to vial and injected into UPLC-quadrupole/electrostatic field orbitrap mass spectrometer system under full $\mathrm{ms} /$ $\mathrm{dd}-\mathrm{ms}^{2}$ optimized conditions for each compound.

\section{Goat dried milk}

The goat dried milk ( $0.45 \mathrm{~g})$ was weighed in a centrifuge tube $(50 \mathrm{~mL})$ and dissolved with $3 \mathrm{~mL}$ water $\left(40-50{ }^{\circ} \mathrm{C}\right)$. Next, 7 $\mathrm{mL}$ of acetonitrile with $0.2 \%$ formic acid was added as an extraction solvent, and the tube was vigorously mixed for $30 \mathrm{~s}$. The tube was then immediately shaken for $30 \mathrm{~min}$ and then centrifuged for $20 \mathrm{~min}$ at $10,000 \mathrm{r} / \mathrm{min}$ at $4{ }^{\circ} \mathrm{C}$. The upper layer was submitted to a PRiME HLB. All elutes were collected into a centrifugal tube and evaporated under nitrogen gas at $40{ }^{\circ} \mathrm{C}$. The residue was added with $1 \mathrm{~mL}$ acetonitrile: $0.1 \%$ formic acid solution $(1: 9, \mathrm{v} / \mathrm{v})$, and filtered with a 0.22 $\mu \mathrm{m}$ filter membrane. The final extract solution was analyzed like the goat milk samples.

\section{UPLC-quadrupole /electrostatic field orbitrap mass analysis}

The analytes were measured with an ultra-high performance liquid chromatography system (Ultimate 3000, USA) coupled with a quadrupole/electrostatic field orbitrap mass spectrometer (Thermo \&Fisher Q Exactive, USA). A Thermo Hypersil GoldaQ $(2.1 \times 100 \mathrm{~mm}, 1.9$ $\mu \mathrm{m})$ column was used for separation. Mobile phase consisting of elute A (water, $0.1 \%$ formic acid) and elute B (acetonitrile) was used at a flow rate of $0.3 \mathrm{~mL} / \mathrm{min}$. All analytes were separated using gradient method: $0-1$ min: $10 \%$ B; $1-6$ min: $10 \%$ B to $80 \%$ B; $6-8$ min: $80 \%$ B; 8.1-12 min: $10 \%$ B. The optimized sample injection volume was set at $10 \mu \mathrm{L}$. All 62 target analytes ware eluted over 0-6 min while the last 6 min were used for column cleaning and re-equilibration.

The quadrupole/electrostatic field orbitrap was equipped with a heated electrospray ionization (HESI) source. The temperature of the HESI was $350{ }^{\circ} \mathrm{C}$, the capillary temperature was $320{ }^{\circ} \mathrm{C}$, and the spray voltage was $3.8 \mathrm{kV}$

Table 2 Matrix effect (ME) for 60 veterinary antibiotic residues spiked in blank milk and milk power sample for individual donors ( $n$ $=5$ )

\begin{tabular}{|c|c|c|c|c|c|c|c|c|c|c|c|}
\hline \multirow[t]{3}{*}{ No. } & \multirow[t]{3}{*}{ Compound } & \multicolumn{2}{|c|}{ Sample type } & \multirow[t]{3}{*}{ No. } & \multirow[t]{3}{*}{ Compound } & \multicolumn{2}{|c|}{ Sample type } & \multirow[t]{3}{*}{ No. } & \multirow[t]{3}{*}{ Compound } & \multicolumn{2}{|c|}{ Sample type } \\
\hline & & Milk & $\begin{array}{l}\text { Milk } \\
\text { power }\end{array}$ & & & Milk & $\begin{array}{l}\text { Milk } \\
\text { power }\end{array}$ & & & Milk & $\begin{array}{l}\text { Milk } \\
\text { power }\end{array}$ \\
\hline & & $\begin{array}{l}10 \mu \mathrm{\mu g} / \\
\mathrm{kg}(\mathrm{ME} \\
\%)\end{array}$ & $\begin{array}{l}10 \mu \mathrm{g} / \\
\mathrm{kg}(\mathrm{ME} \\
\%)\end{array}$ & & & $\begin{array}{l}10 \mu \mathrm{g} / \\
\mathrm{kg}(\mathrm{ME} \\
\%)\end{array}$ & $\begin{array}{l}10 \mu \mathrm{g} / \\
\mathrm{kg}(\mathrm{ME} \\
\%)\end{array}$ & & & $\begin{array}{l}10 \mu \mathrm{\mu g} / \\
\mathrm{kg}(\mathrm{ME} \\
\%)\end{array}$ & $\begin{array}{l}10 \mu \mathrm{\mu g} / \\
\mathrm{kg}(\mathrm{ME} \\
\%)\end{array}$ \\
\hline 1 & Sulfaguanidine & 115.2 & 90.6 & 21 & Sulfamethizole & 107.6 & 88.8 & 41 & Ornidazole & 106.1 & 88.8 \\
\hline 2 & $\begin{array}{l}\text { 2-Methyl-5- } \\
\text { nitroimidazole }\end{array}$ & 101.5 & 115.3 & 22 & Sulfamethoxydiazine & 93.5 & 99.9 & 42 & Sulfamethoxazole & 115.0 & 97.6 \\
\hline 3 & Metronidazole & 100.9 & 117.0 & 23 & Ciprofloxacin & 93.5 & 92.8 & 43 & Sulfisoxazole & 114.0 & 99.6 \\
\hline 4 & Cefapirin & 90.2 & 87.5 & 24 & Dimetridazole & 99.2 & 108.7 & 44 & Ipronidazole & 101.8 & 100.2 \\
\hline 5 & Sulfadiazine & 118.8 & 115.0 & 25 & Marbofloxacin & 101.8 & 101.9 & 45 & Doxycycline & 102.6 & 114.1 \\
\hline 6 & Sulfapyridine & 117.5 & 115.0 & 26 & Fleroxcain & 89.7 & 101.1 & 46 & Ceftiofur & 110.1 & 114.0 \\
\hline 7 & Lincomycin & 104.8 & 107.6 & 27 & Orbifloxacin & 91.5 & 109.3 & 47 & Sulfaquinoxaline & 114.1 & 95.1 \\
\hline 8 & Sulfathiazole & 109.3 & 114.5 & 28 & Enrofloxacin & 106.2 & 97.0 & 48 & Sulfaphenazole & 106.1 & 112.5 \\
\hline 9 & Sulfamerazine & 94.4 & 114.0 & 29 & Sulfamethoxypyridazine & 85.7 & 104.3 & 49 & Sulfadimoxine & 105.6 & 97.2 \\
\hline 10 & Ampicillin & 114.4 & 92.6 & 30 & Sparfloxacin & 96.1 & 114.0 & 50 & Erythromycin & 113.0 & 100.3 \\
\hline 11 & Penicillin G & 109.4 & 111.1 & 31 & Demethylchlortetracycline & 102.3 & 114.8 & 51 & Tilmicosin & 101.3 & 111.5 \\
\hline 12 & Trimethoprim & 101.4 & 104.5 & 32 & Sulfachlorpyridazine & 97.0 & 109.6 & 52 & Penicillin V & 107.2 & 112.0 \\
\hline 13 & Metronidazole-OH & 110.4 & 113.0 & 33 & Difloxacin & 95.5 & 115.4 & 53 & Tylosin & 82.1 & 110.0 \\
\hline 14 & Norfloxacin & 89.7 & 100.5 & 34 & Chlorotetracycline & 92.6 & 114.0 & 54 & Flumequine & 90.8 & 111.2 \\
\hline 15 & Lomefloxacin & 106.5 & 94.4 & 35 & Spiramycin & 90.2 & 92.8 & 55 & Nalidixic acid & 86.3 & 102.1 \\
\hline 16 & Enoxacin & 112.8 & 100.2 & 36 & Ipronidazole-OH & 104.3 & 99.4 & 56 & Oxacillin & 114.0 & 106.2 \\
\hline 17 & Ofloxacin & 92.5 & 96.1 & 37 & Sulfadimethoxypyrimidine & 104.7 & 84.3 & 57 & Cloxacillin & 102.2 & 92.3 \\
\hline 18 & Pefloxacin & 98.5 & 99.2 & 38 & Sarafloxacin & 92.5 & 110.0 & 58 & Dicloxacillin & 101.6 & 110.6 \\
\hline 19 & Danofloxacin & 91.2 & 98.3 & 39 & Nafcillin & 98.8 & 94.5 & 59 & Roxithromycin & 100.7 & 106.4 \\
\hline 20 & Sulfadimethoxine & 103.6 & 97.6 & 40 & Clindamycin & 105.4 & 113.0 & 60 & Josamycin & 96.3 & 107.7 \\
\hline
\end{tabular}


for positive mode. All other quantitative data were acquired in full scan mode. Full MS/dd-MS ${ }^{2}$ was used for qualitative analysis. Precursor ions were selected by the quadrupole sent to the S-Lens in consideration of the detection of target analytes. The productions were then obtained from fragmented precursor ions via normalized collision energy (NCE).

The MS parameters of full MS/dd-MS ${ }^{2}$ were as follows: Full MS, inclusion on, resolution 70,000, maximum IT $200 \mathrm{~ms}$, and AGC target $3.0 \mathrm{e}^{6}$. The dd-MS settings were as follows: inclusion on, resolution 17,500, maximum IT $6 \mathrm{~ms}$, AGC target $2.0 \mathrm{e}^{5}$, and isolation window $2.0 \mathrm{~m} / z$. The accurate masses for the precursor ions and productions are shown in Table 1.

\section{Validation}

The method was validated according to the EU Commission 2002/657/EC. The blank milk matrix samples were carefully selected to account for the possible variation within a given matrix(e.g., fat content, protein content, and other organics). The method was evaluated for linearity, limit of detection (LOD), precision, and accuracy. In the experiment, matrixmatched instead of internal standard was used because of the level of matrix effects can by significantly reduced by matrixmatched calibration curve (Table 2). At the same time, internal standard can be found in a few antibiotics. A matrixmatched calibration curve was established for each target antibiotics separately. Six calibration levels were prepared by spiking the blank matrix with each antibiotic. The coefficients of determination $\left(r^{2}\right)$ were higher than 0.99 in all matrices. The veterinary antibiotics were divided into two groups according to the response value of each target analyte to mass spectrometry. Group1 included erythromycin, spiramycin, roxithromycin, TIL, TYL, clindamycin, CLT, DEM, ceftiofur, cefapirin, OXAC, DICL, CLOX, NAFC, AMPI, PEG, and PEV with the following spiking levels: 10,20 , and $50 \mu \mathrm{g} / \mathrm{kg}$. Group 2 included SMZ, sulfathiazole, TMP, sulfamethizole, SIZ, SD, sulfachlorpyridazine, sulfamethoxydiazine, sulfamethazine, sulfaquinoxaline, SDM, sulfamethoxypyridazine, sulfadimethoxypyrimidine, SPD, SMX, sulfaguanidine, sulfaphenazole, LOM, CIP ENR, OFX, NOR, ORB, DAN, SPA, SAR, MAR, ENO, FLU, FLE, DIF, PEF, nalidixic acid, LIN, dimetridazole, metronidazole- $\mathrm{OH}$, ipronidazole- $\mathrm{OH}$, ipronidazole, ornidazole, metronidazole, 2-methyl-5-nitroimidazole, doxycycline, and josamycin with the following spiking levels: 5,10 , and $20 \mu \mathrm{g} / \mathrm{kg}$. The accuracy was determined with recovery experiments using blank samples at LOQ spiking levels in triplicate. The repeat ability was evaluated via the relative standard deviation (RSD, \%). The limits of detection

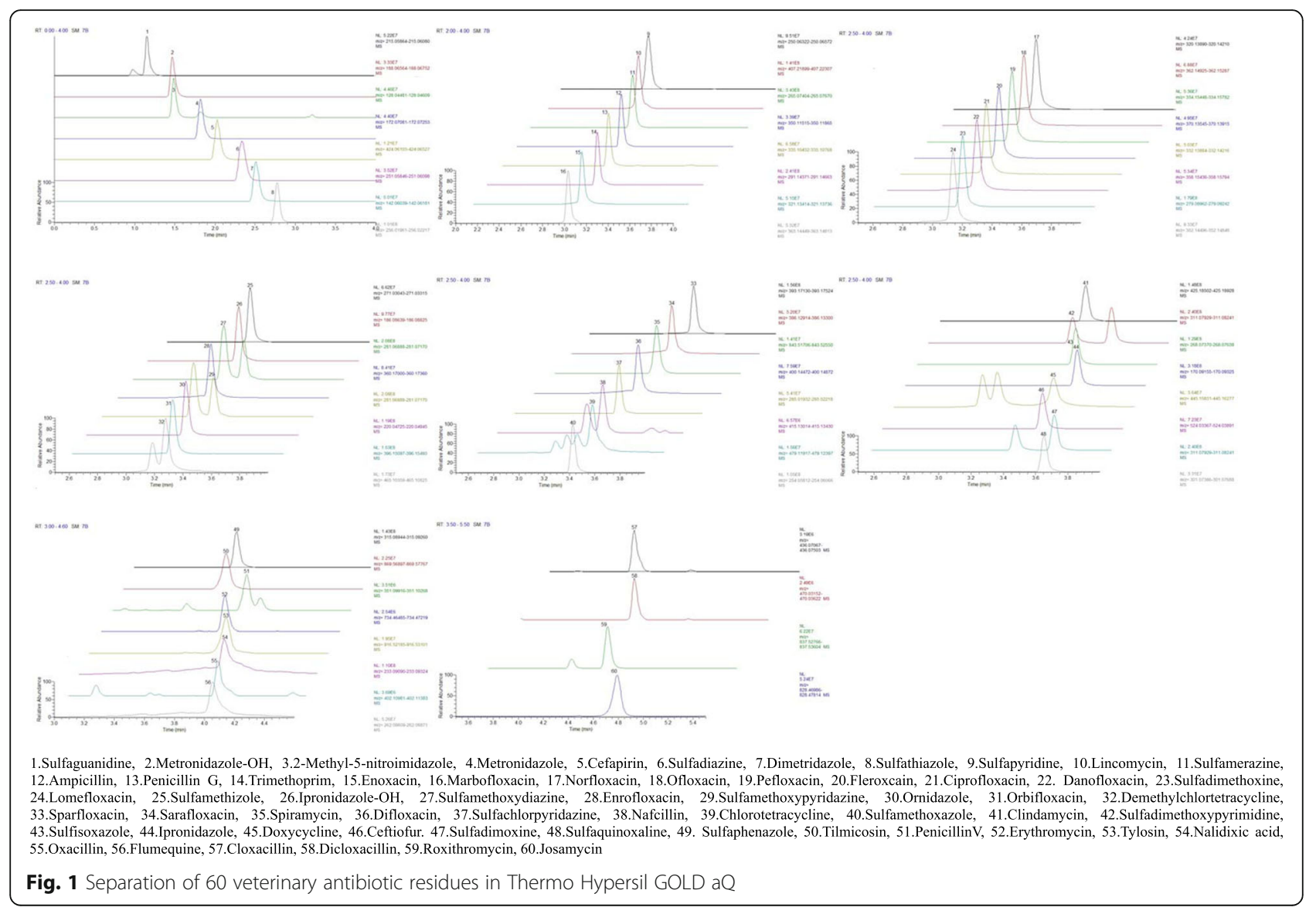


(LOD) and quantification (LOQ) were defined as lowest concentrations with a signal-to-noise $(\mathrm{S} / \mathrm{N})$ ratio of 3 for LOD or 10 for LOQ.

The matrix effect (ME) was investigated by comparing the peak area of each antibiotic spiked in blank sample after extraction procedure at same concentration level, with peak area of each antibiotic in water (without matrix matched) at the same concentration. The peak area of each antibiotic in water was set at 100\% (Javorska et al. 2017).

\section{Results and discussion}

\section{Optimization of the UPLC-quadrupole/electrostatic field orbitrap conditions}

Ultra-performance chromatography columns with sub$2-\mu \mathrm{m}$ particles have outstanding separation capacity. They have facilitated the development of quantification methods for multi-residues within a short run time. Here, different types of chromatographic columns were investigated. Under the same determination conditions, DICL and PEV were weak retention on a Waters ACQUITY UPLC BEH Shield RP $18(100 \mathrm{~mm} \times 2.1$ $\mathrm{mm}, 1.7 \mu \mathrm{m}$ ), and CLOX and OXAC were unreserved on a Waters ACQUITY UPLC ${ }^{\circ}$ HSS T3 column (100 $\mathrm{mm} \times 2.1 \mathrm{~mm}, 1.8 \mu \mathrm{m})$. However, the Thermo Hypersil GOLD aQ $(100 \mathrm{~mm} \times 2.1 \mathrm{~mm}, 1.9 \mu \mathrm{m})$ showed good performance in the separation of 60 veterinary antibiotics. The analysis process was completed within $12 \mathrm{~min}$ (Fig. 1).
Different solvents were tested to achieve better separation and retention of target analytes including cetonitrile, methanol, and $0.1 \%$ formic acid aqueous solutions. There needed to be some compromise between mobile phase composition and MS response for the 60 selected veterinary antibiotics. Consideration of the sensitivity (S/ $\mathrm{N})$ and the peak shape showed that the target analytes had better performance in acetonitrile than in methanol. When the aqueous solution was water, the peaks of quinolones, macrolides, and tetracyclines were asymmetrical and heavy-trailed. However, the shape of peak and the retention were well when formic acid was added into the aqueous solution. This is because the addition of formic acid improved the ionization efficiency. Therefore, acetonitrile and $0.1 \%$ formic acid were selected as the mobile phase.

The optimum mass spectrometric parameters for the identification and quantification of 60 veterinary antibiotics were obtained after analyzing the compounds by flow injection analysis. The sensitivity of target analytes was investigated via the chromatograms in full scan mode in positive ionization mode. Due to adduct formation with formic acid, all analytes showed strong formic/ hydrogen adduct species $\left([\mathrm{M}+\mathrm{H}]^{+}\right)$; these species appear to be the precursor ions in the mass spectrum. The target analytes could achieve better base separation with the interference peak. This was more efficient and lowered the matrix effects, thereby leading to a resolution of 70,000 versus 17,500 .

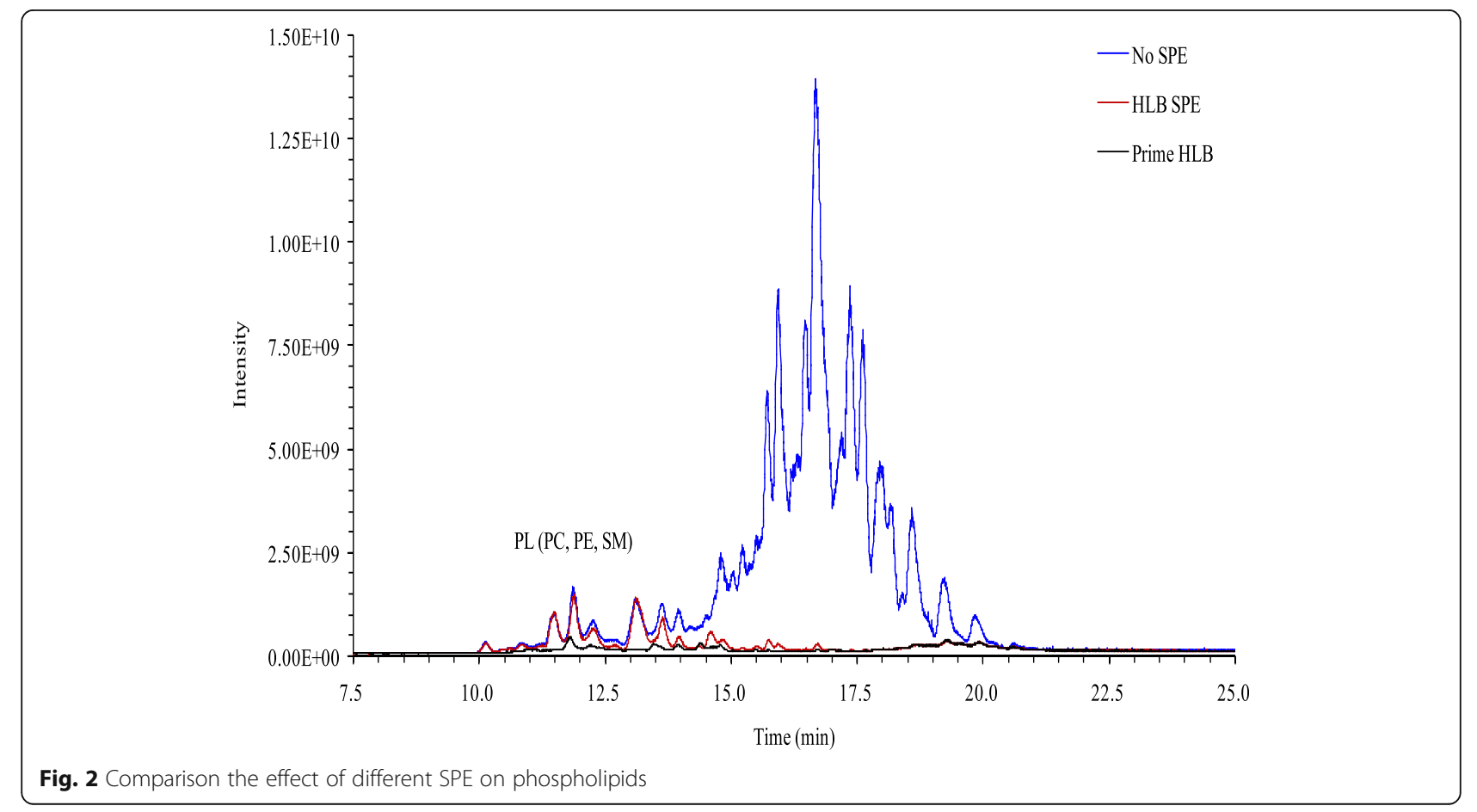


The full MS/dd-MS ${ }^{2}$ mode led to a production spectrum with accurate mass measurement according to the inclusion list (a list of targeted accurate masses). This was defined as a data-dependent acquisition (dd$\mathrm{MS}^{2}$ ). After full scan analysis, specific mass windows were extracted to screen the data for the presence of analytes. The effect of the isolation window on analyte selectivity was tested. The best results were achieved when an isolation window of $2.0 \mathrm{ppm}$ was employed. Table 1 shows the optimal parameters of the UPLCquadrupole/electrostatic field orbitrap.

\section{Optimization of the extraction procedure}

According to these reports, milk and dried milk contained a great deal of phospholipids. Two different solidphase extraction (SPE) columns (PRiME HLB and OasisHLB) were compared to reduce the phospholipids of the milk samples. Twelve blank milk samples were prepared following the "Sample preparation" section; four of the samples were not treated with solid phase extraction columns, four were treated with HLB, and the last four were purified with PRiME HLB. All of these samples were injected into a UPLC-quadrupole/electrostatic field orbitrap analysis in full MS mode to acquire identifies phospholipids in milk.

Although the high-resolution quadrupole/electrostatic field orbitrap is selective, the complicated matrix can still affect target analyte ionization; this leads to ion suppression or enhancement. The recovery of veterinary antibiotics in the Oasis HLB column tailed off at 25\% versus the PRiME HLB. Many components, such as phospholipids, aminoacids, and fat, in milk can lead to interference of mass response. As such, these components were not effectively removed by the PRiME HLB column.

Figure 2 shows that the peak intensities of phospholipids were significantly different among the three treatment modes. The peak intensities of these compounds were not influenced by HLB purification in milk samples versus untreated milk samples. The peak intensities of phospholipids significantly decreased, which confirmed that one step of pretreating milk samples by PRiME HLB led to effective removal of phospholipids for the high-throughput detection of multiple veterinary antibiotic residues.

Previous studies showed that PRiME HLB removes phospholipids from milk via a single pretreatment step. There are no pre-equilibration and washing steps before eluting from the SPE. The effects of purifying the phospholipids including via absorption were compared for the SPE.

Here, different extraction solvents (pure acetonitrile, acetonitrile acidified with formic acid, or water) were evaluated, considering the acidic or basic character of these veterinary antibiotics. Commission Decision 2002/657/EC and GB/T 27404-2008 were used as guidelines to calculate recoveries and matrix effects (Fig. 3). Many target analytes had low recovery with $80 \%$ aqueous acetonitrile. Probably,

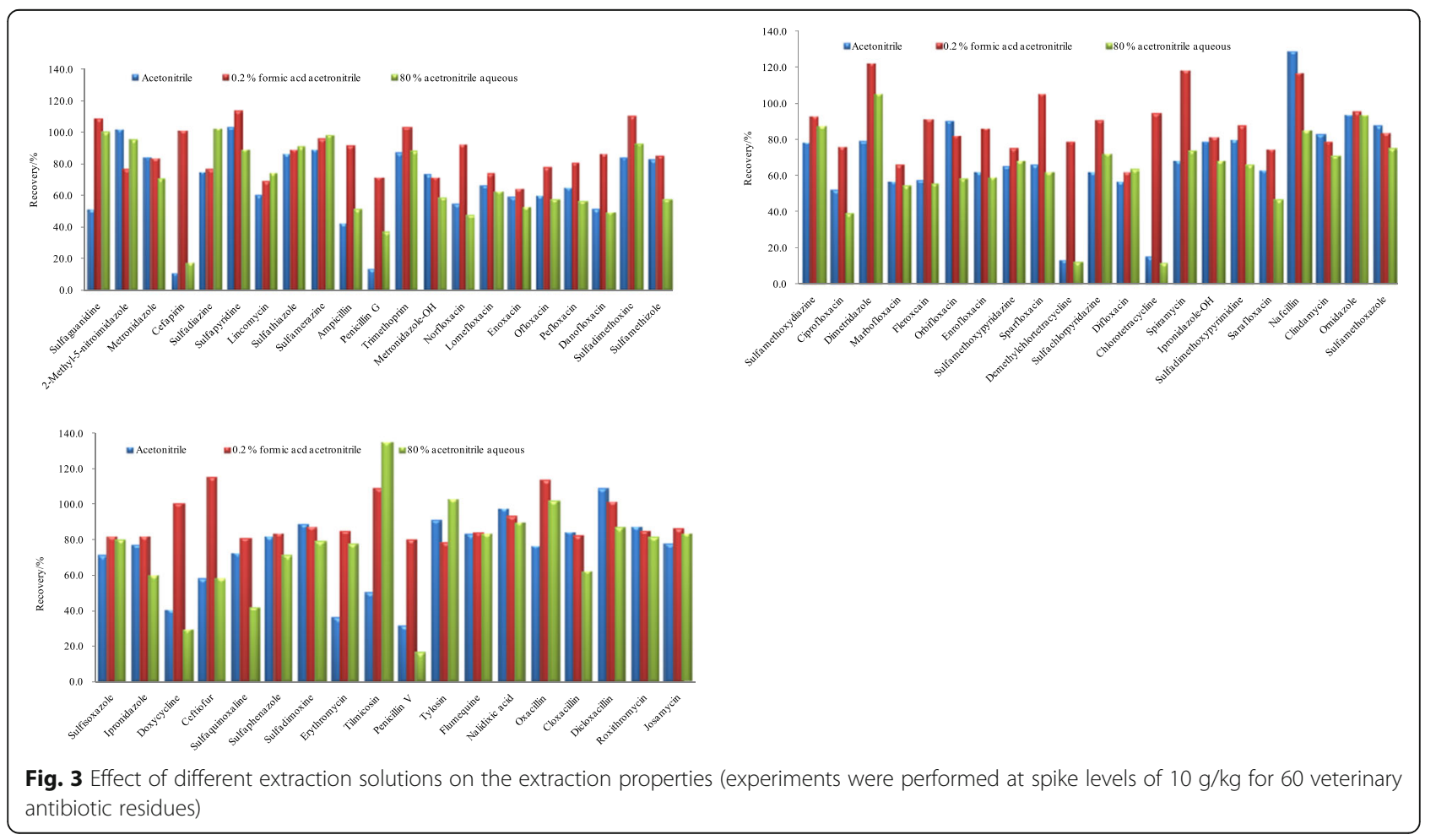




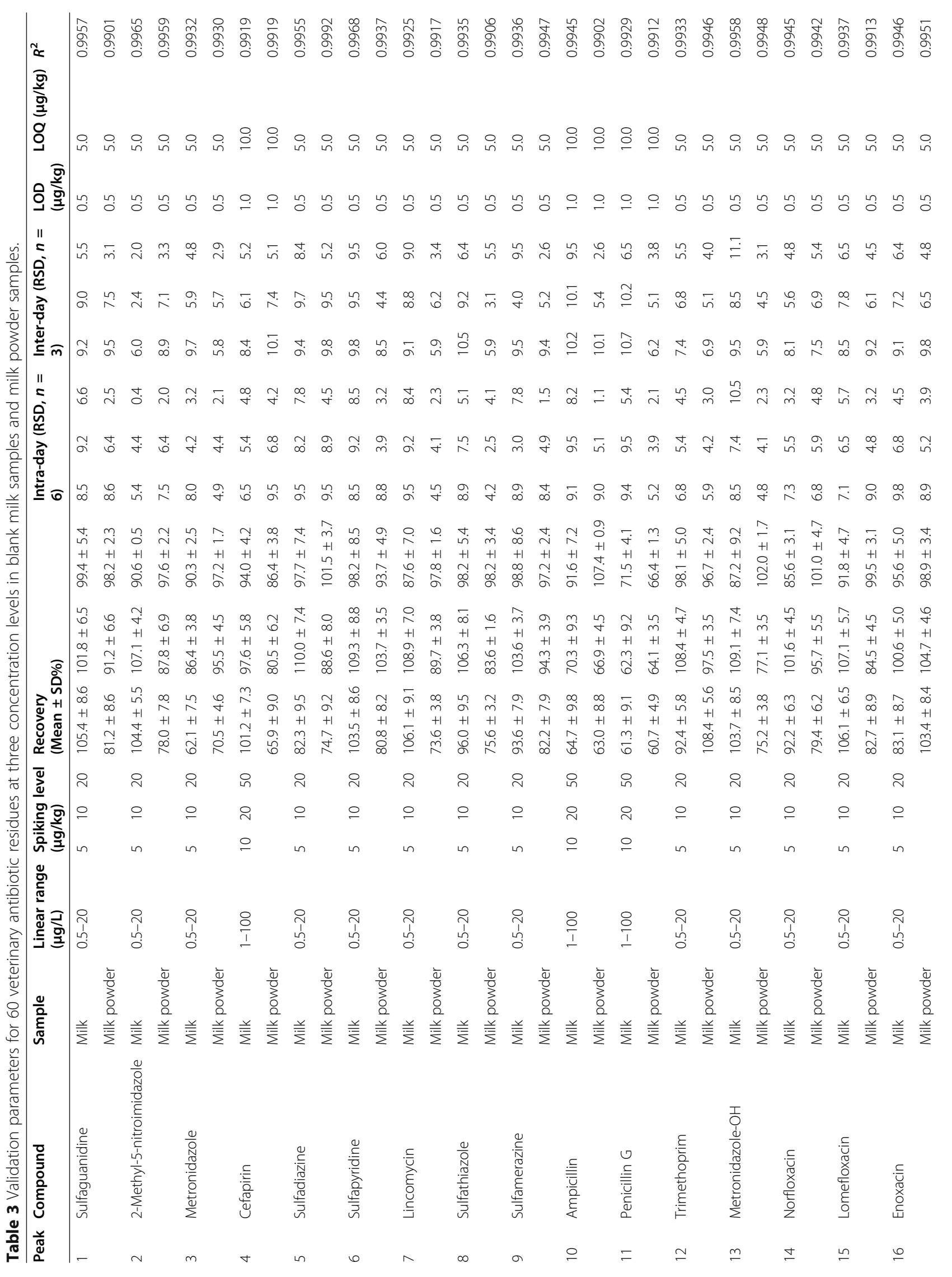




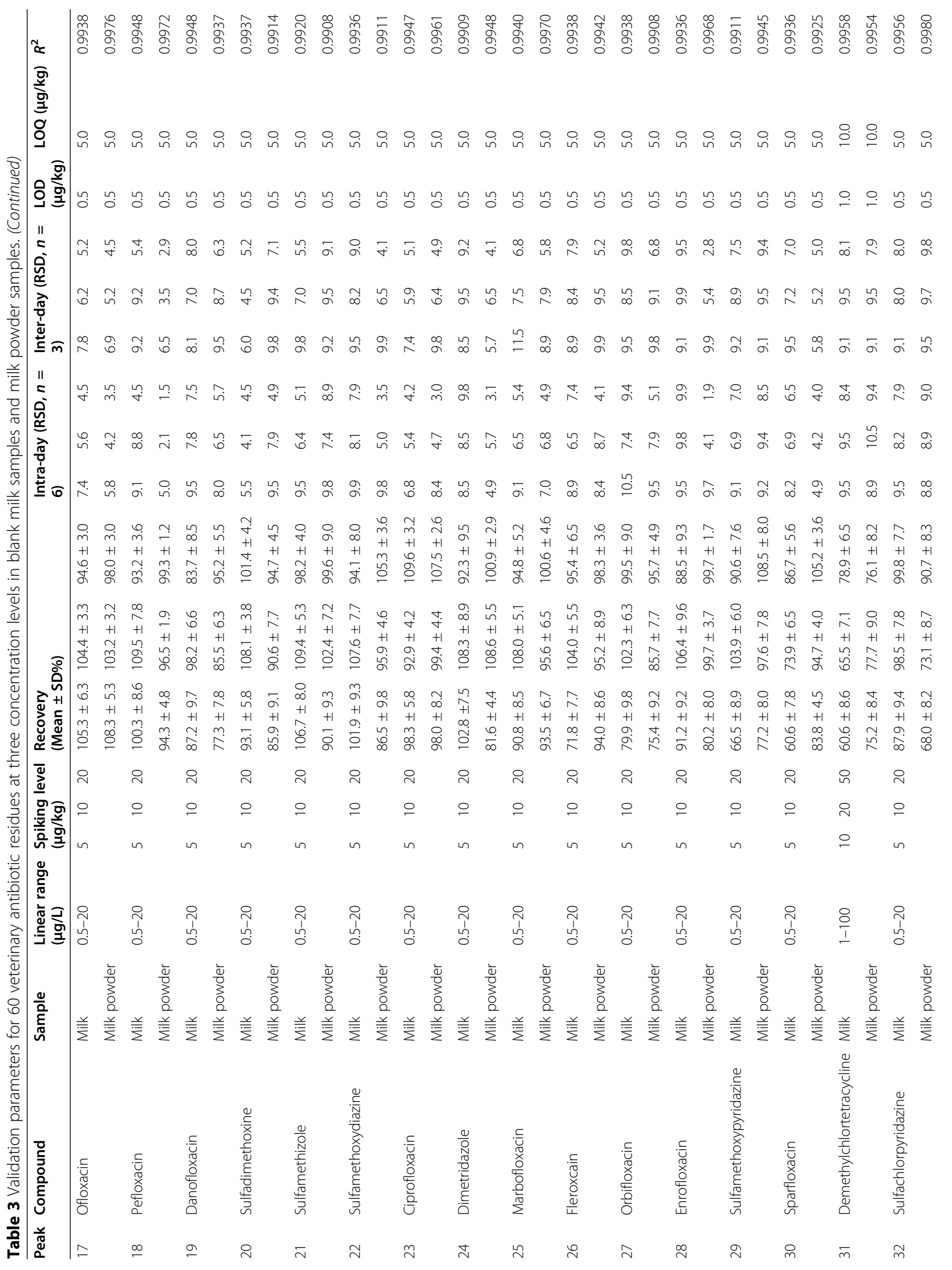









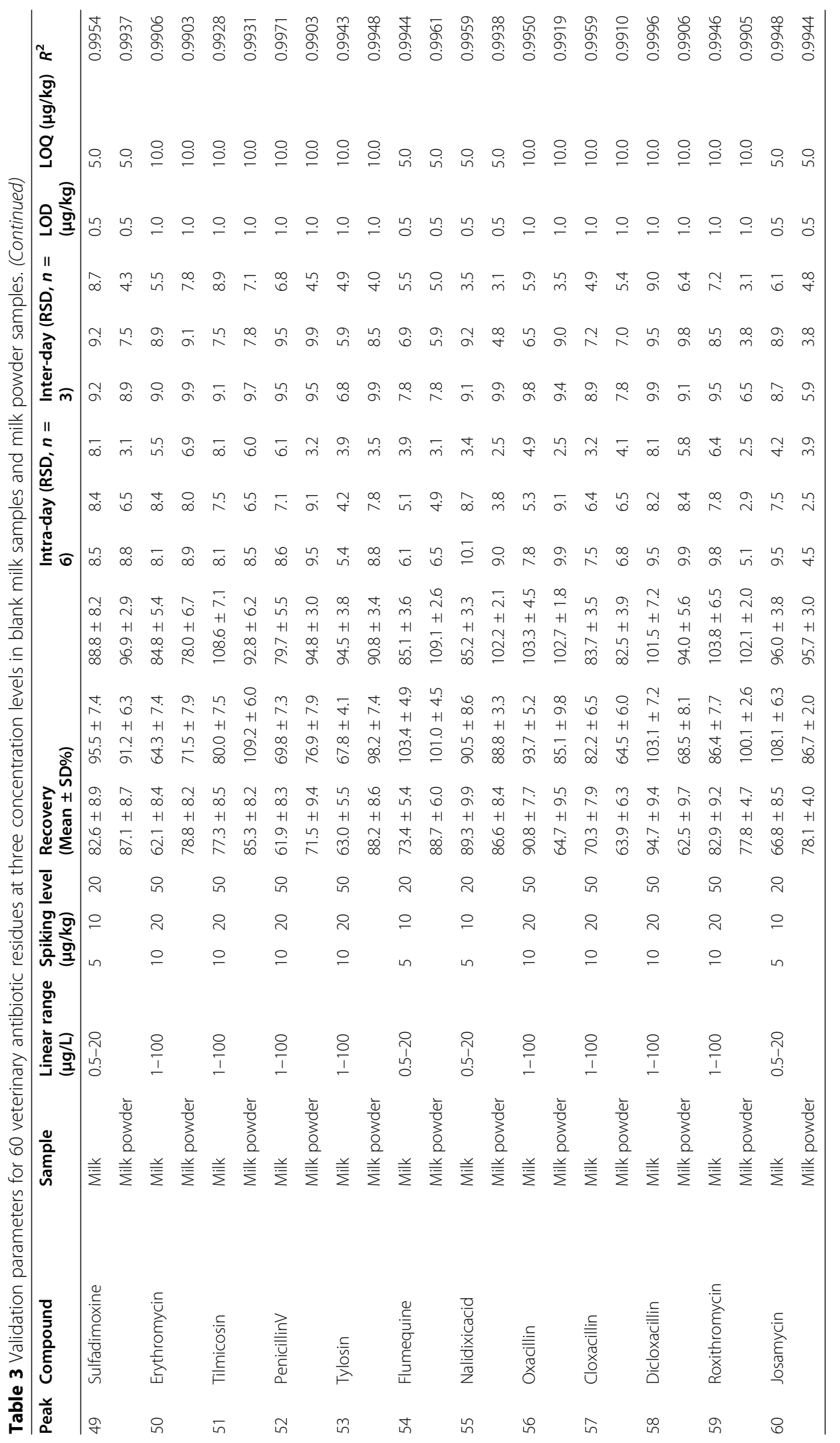


the effect of precipitation of protein was weakened in acetonitrile aqueous solution, in which caused higher matrix effect and lower extraction recoveries. Acidic acetonitrile and pure acetonitrile both had good recoveries for most veterinary antibiotics. These results indicated that these solvents could prevent the interference of proteins and phospholipids. However, certain antibiotics (e.g., cefapirin, penicillin G, demethylchlortetracycline, chlorotetracycline, doxycycline, erythromycin, and penicillin V) had recoveries that were too low (below 50\%) with pure acetonitrile. It was difficult to extract some highly polar components such as $\beta$-lactams when the concentration of acetonitrile in the solvent was too high. Therefore, acidic acetonitrile could be used for extraction. The $0.2 \%$ formic acid acetonitrile extracted more than $95 \%$ veterinary antibiotics spiked into blank milk samples and precipitated protein in milk sample; these results were better than extracted by pure acetonitrile.

\section{Method validation}

PRiME HLB could eliminate the matrix effects, and matrix-matched calibration was also used to reduce the impact of matrix effects on precision and accuracy of the UPLC-quadrupole/electrostatic field orbitrap mass method.

The ME was calculated via the method in the "Validation" section. The result showed that the ME was established for each antibiotic spiked into milk and dried milk sample was not higher than $15 \%$. Therefore, the matrixmatched calibration was applied for these matrices instead of internal standard. The results showed the matrix matched calibration can corrected the level of matrix effects (Table 2).

The resultant matrix-matched calibration curves using the instrument response were linear from 0.5 to $20 \mu \mathrm{g} / \mathrm{L}$ for sulfanilamides, quinolones, and nitroimidazoles. The range was $1-100 \mu \mathrm{g} / \mathrm{L}$ for tetracyclines, macrolides, and $\beta$-lactams. The response function was linear with a coefficient $\left(r^{2}\right)$ of $0.9906-0.9971$ for milk samples and 0.9901-0.9998 for dried milk samples (Table 3).The sensitivity was evaluated via the limit of detection (LOD) and limit of quantification (LOQ). The LOQs were calculated at a signal-to-noise ratio $(\mathrm{S} / \mathrm{N})$ of 10 ; LODs used $\mathrm{S} / \mathrm{N}$ of 3. These data are shown in Table 3.The LODs were 0.5 to $1.0 \mu \mathrm{g} / \mathrm{kg}$ and the LOQs ranged from 5.0 to $10.0 \mu \mathrm{g} / \mathrm{kg}$.

The intra-day and inter-day relative standard deviations (RSDs) were adopted for precision validation. The intra-day precision was evaluated via three repeated analyses at different concentrations on three sequential runs with six replicates. The inter-day precision was performed by analyzing spiked samples over five days. The RSDs were $0.4 \%$ to $10.5 \%$ for intra-day and $2.0 \%$ to $11.5 \%$ for inter-day experiments; these values were all less than $15 \%$. It indicated that the developed method was reliable and reproducible within its analytical range.

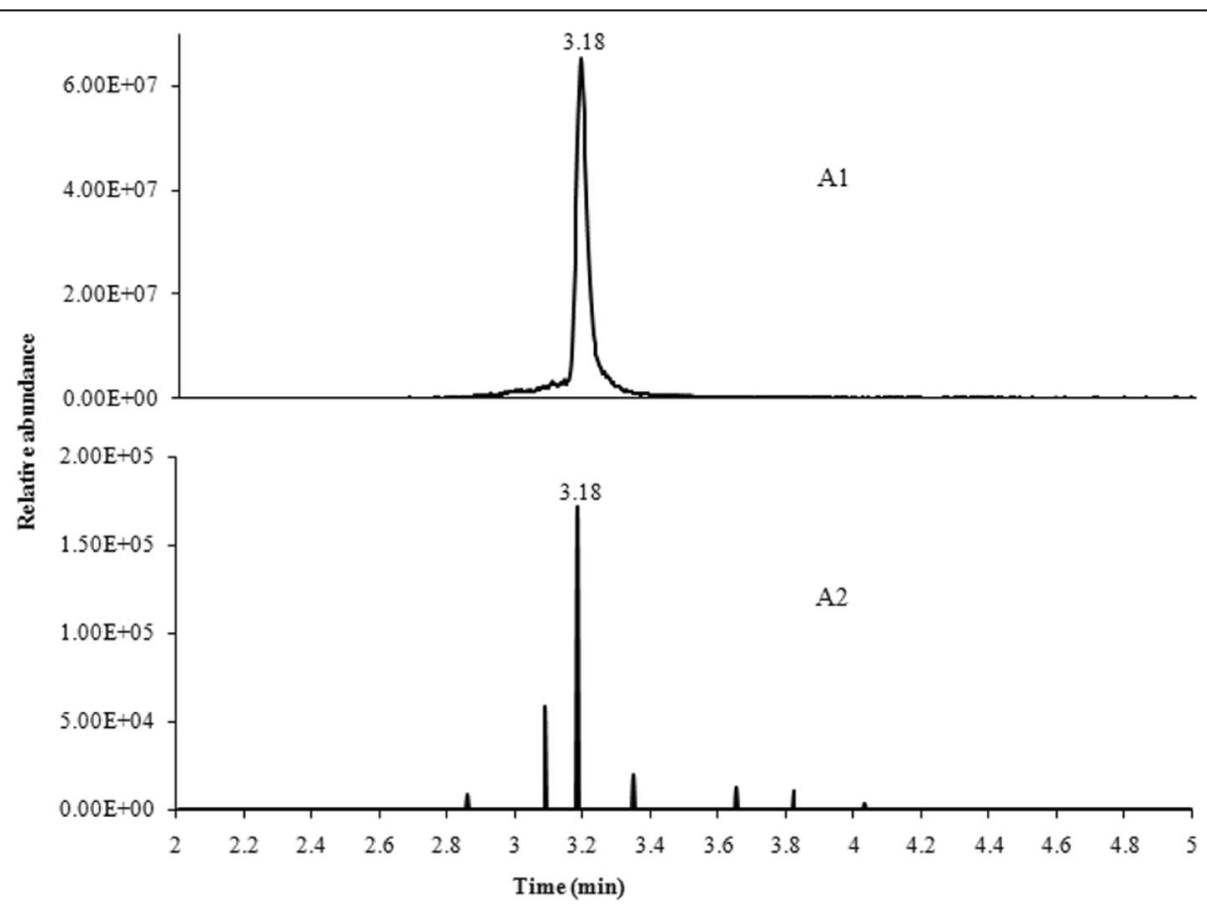

Fig. 4 Example of typical chromatography and spectra from a full MS/dd-MS ${ }^{2}$ experiment: (A1) extracted ion chromatogram of enrofloxacin $[M+$ $\mathrm{H}^{+} \mathrm{m} / \mathrm{z} 360.17081$ in sample N0. 17; (A2) dd-MS total ion chromatogram of enrofloxacin of $[\mathrm{M}+\mathrm{H}]^{+} \mathrm{m} / \mathrm{z} 245.10895$ in sample No. 17 
The recoveries were assessed by spiking blank dairy samples at three concentration levels (LOQs, $2 \times$ LOQs, $4 \times$ LOQs) with six replicate sat each level. The average recoveries were $60.6-110.0 \%$ for milk samples in all fortification levels; the values were $60.1-109.6 \%$ for dried milk samples.

Figure 4 shows the typical chromatograms from a full MS/dd-MS ${ }^{2}$ experiment of analytes detected in positive samples. With the UPLC-quadrupole/electrostatic field orbitrap high-resolution mass spectrometry method, not only accuracy was enhanced but also the low concentration antibiotic residues; this suggests that the UPLCquadrupole/electrostatic field orbitrap high-resolution mass spectrometry method was appropriate for the screening of antibiotic residues in milk and dried milk samples.

\section{Method applications}

Next, 25 goat milk and 35 dried milk samples were collected from local dairy farms in Shaanxi province, China. Traces of three veterinary antibiotic residues over allowable levels were detected in six samples: $2.45 \mu \mathrm{g} / \mathrm{kg}, 5.02$ $\mu \mathrm{g} / \mathrm{kg}$ of metronidazole in sample No. 3 (goat milk) and No. 15 (goat milk), and $112.4 \mu \mathrm{g} / \mathrm{kg}$ of enrofloxacin (goat milk) in sample No.17. These results suggest that onestep extraction by PRiME HLB combined with UPLCquadrupole/electrostatic field orbitrap high-resolution mass spectrometry for milk products is a simple and effective method for analyses in goat milk and goat dried milk samples.

\section{Conclusions}

A methodology for the analysis of veterinary antibiotic residues in goat milk products based on PRiME HLB extraction combined with UPLC-quadrupole/electrostatic field orbitrap high-resolution mass spectrometry. The method can achieved the simultaneous analysis of sixtytwo veterinary antibiotics belong to six different classification. The method showed good performance on recoveries, precision, accuracy, MDL, and MQL, proving the effectiveness of the methodology for analysis these compounds. Compared with traditional methods, the sensitivity was enhanced, and the accuracy was improved, leading to effective method for screening antibiotic residues in milk products.

\section{Supplementary Information}

The online version contains supplementary material available at https://doi. org/10.1186/s40543-021-00268-4.

Additional file 1. National food safety standard-Maximum residue limits for veterinary drugs in foods.

\section{Abbreviations}

SMZ: Sulfamerazine; TMP: Trimethoprim; SIZ: Sulfisoxazole; SD: Sulfadiazine; SDM: Sulfadimoxine; SPD: Sulfapyridine; SMX: Sulfamethoxazole;
LOM: Lomefloxacin; CIP: Ciprofloxacin; ENR: Enrofloxacin; OFX: Ofloxacin; NOR: Norfloxacin; ORB: Orbifloxacin; DAN: Danofloxacin; SPA: Sparfloxacin; SAR: Sarafloxacin; MAR: Marbofloxacin; ENO: Enoxacin; FLU: Flumequine; FLE: Fleroxacin; DIF: Difloxacin; PEF: Pefloxacin; LIN: Lincomycin;

TIL: Tilmicosin; TYL: Tylosin; CLT: Chlortetracycline; DOX: Doxycycline; DEM: Demeclocycline; TIL: Ceftiofur; OXAC: Oxacillin; DICL: Dicloxacillin; CLOX: Cloxacillin; NAFC: Nafcillin; AMPI: Ampicillin; PEG: Penicillin G; PEV: Penicillin $V$

\section{Acknowledgements}

This study was supported by the Technology Program of Shaanxi Entry and Exit Inspection and Quarantine Bureau (Shaan K-201606), the Science and Technology Resource Opening Sharing Platform of Shaanxi Province (2017KTPT-06), Science and Technology Project of General Administration of Customs, P. R. China (Grant No. 2018IK057), and Shaanxi Key Research \& Development Program (2017NY-165).

\section{Authors' contributions}

LZ contributed to the conception of the study and data analyses and wrote the manuscript. LS performed the experiment. QH contributed significantly to analysis and manuscript preparation. YL helped perform the analysis with constructive discussions. The authors read and approved the final manuscript.

\section{Funding}

Technology Program of Shaanxi Entry and Exit Inspection and Quarantine Bureau (ShaanK-201606), Science and Technology Resource Opening Sharing Platform of Shaanxi Province (2017KTPT-06), Science and Technology Project of General Administration of Customs, P. R. China (Grant No. 2018IK057), Shaanxi Key Research \& Development Program (2017NY-165).

\section{Availability of data and materials}

The data sets supporting the results of this article are included within the article and its additional files.

\section{Declarations}

Competing interests

The authors declared that they have no competing interests.

\section{Author details}

'Technology Centre of Xi'an Customs District P. R. China, Xi'an 710068, China. ${ }^{2}$ School of Electronic and Information Engineering, Xi'an Technological University, Xi'an 710021, China.

Received: 23 September 2020 Accepted: 4 March 2021

Published online: 24 March 2021

\section{References}

Abdallah MAE, Nguyen KH, Ebele AJ, Atia NN, Ali HRH, Harrad S. A single run, rapid polarity switching method for determination of 30 pharmaceuticals and personal care products in waste water using Q-Exactive Orbitrap high resolution accurate mass spectrometry. J Chromatogr A. 2019;1588:68-76. https://doi.org/10.1016/j.chroma.2018.12.033.

Berendsen BJA, Meijer T, Mol HGJ, Ginkel LV, Nielen MW. A global inter-laboratory study to assess acquisition modes for multi-compound confirmatory analysis of veterinary drugs using liquid chromatography coupled to triple quadrupole, time of flight and orbitrap mass spectrometry. Anal Chim Acta. 2017;962:60-72. https://doi.org/10.1016/j.aca.2017.01.046.

Cámara M, Picó G, Garcinuńo MR. Fernández-Hernado, Durand-Alegría, Sánchez PJ. An HPLC-DAD method for the simultaneous determination of nine $\beta$ lactam antibiotics in ewe milk. Food Chem. 2013;141(2):829-34. https://doi. org/10.1016/j.foodchem.2013.02.131.

Casado J, Brigden K, Santillo D, Johnston P. Screening of pesticides and veterinary drugs in small streams in the European Union by liquid chromatography high resolution mass spectrometry. Sci Total Environ. 2019; 670:1204-25. https://doi.org/10.1016/j.scitotenv.2019.03.207.

Casado J, Santillo D, Johnston P. Multi-residue analysis of pesticides in surface water by liquid chromatography quadrupole-Orbitrap high resolution tandem mass spectrometry. Anal Chim Acta. 2018;1024:1-17. https://doi. org/10.1016/j.aca.2018.04.026. 
Chen Q, Pan XD, Huang BF, Han JL. Quantification of $16 \beta$-lactams in chicken muscle by QuEChERS extraction and UPLC-Q-Orbitrap-MS with parallel reaction monitoring. J Pharm Biomed Anal. 2017;145(3399):525-30. https:// doi.org/10.1016/j.jpba.2017.07.019.

De Almeida MP, Rezende CP, Ferreira FD, De Souza LF, De Assis DCS, De Figueiredo TC, et al. Optimization and validation method to evaluate the residues of $\beta$-lactams and tetracyclines in kidney tissue by UPLC-MS/MS. Talanta. 2015;144:922-32. https://doi.org/10.1016/j.talanta.2015.07.048.

Dubreil-Chéneau E, Pirotais Y, Verdon E, Hurtaud-Pessel D. Confirmation of 13 sulfonamides in honey by liquid chromatography-tandem mass spectrometry for monitoring plans: validation according to European Union decision 2002/657/EC. J Chromatogr A. 2014;1339(37):128-36. https://doi. org/10.1016/j.chroma.2014.03.003.

Emhofer L, Himmelsbach M, Buchberger W, Klampfl CW. High-performance liquid chromatography drift-tube ion-mobility quadrupole time-of-flight/mass spectrometry for the identity confirmation and characterization of metabolites from three statins (lipid-lowering drugs) in the model plant cress (Lepidium sativum) after uptake from water. J Chromatogr A. 2019;1592:12232. https://doi.org/10.1016/i.chroma.2019.01.049.

Forgacsova A, Galba J, Mojzisova J, Mikus P, Piestansky J, Kovac A. Ultra-high performance hydrophilic interaction liquid chromatography-triple quadrupole tandem mass spectrometry method for determination of cysteine, homocysteine, cysteinyl-glycine and glutathione in rat plasma. J Pharm Biomed Anal. 2019;164:442-51. https://doi.org/10.1016/.jpba.2018.10.053.

Fu Q, Liu DJ, Wang YY, Li XW, Wang LN, Yu FG, et al. Metabolomic profiling of campylobacter jejuni with resistance gene ermB by ultra-high performance liquid chromatography-quadrupole time-of-flight mass spectrometry and tandem quadrupole mass spectrometry. J Chromatogr B. 2018;1079:62-8. https://doi.org/10.1016/j.jchromb.2018.02.009.

GB 31650-2019 National food safety standard-Maximum residue limits for veterinary drugs in foods. (2020).

Han RW, Wang JQ, Zhang N, Xu XM, Zhen YP, Qu XQ, et al. Main risk factor analysis for milk quality and safety III.Veterinary drug residues. China Anim Husbandry Vet Drug Resid. 2012;39:1-4.

Han RW, Zheng N, Yu ZN, Wang J, Xu XM, Qu XY, et al. Simultaneous determination of 38 veterinary antibiotic residues in raw milk by UPLC-MS/MS. Food Chem. 2015;181:119-26. https://doi.org/10.1016/j.foodchem.2015.02.041.

Heller DN, Nochetto CB, Rummel NG, Thomas MH. Development of multiclass methods for drug residues in eggs: hydrophilic solid-phase extraction cleanup and liquid chromatography/tandem mass spectrometry analysis of tetracycline, fluoroquinolone, sulfonamide, and $\beta$-lactam residues. J Agric Food Chem. 2006;54(15):5267-78. https://doi.org/10.1021/jf0605502.

Hu S, Zhao M, Mao Q, Fang C, Chen D, Yan P. Rapid one-step cleanup method to minimize matrix effects for residue analysis of alkaline pesticides in tea using liquid chromatography-high resolution mass spectrometry. Food Chem. 2019;299(June):1-10. https://doi.org/10.1016/j. foodchem.2019.125146.

Javorska L, Krcmova LK, Solich P, Kaska M. Simple and rapid quantification of vancomycin in serum, urine and peritoneal/pleural effusion via UHPLC-MS/ MS applicable to personalized antibiotic dosing research. J Pharm Biomed Anal. 2017;142:59-65. https://doi.org/10.1016/j.jpba.2017.04.029.

Jia W, Chu X, Ling Y, Huang J, Chang J. High-throughput screening of pesticide and veterinary drug residues in baby food by liquid chromatography coupled to quadrupole Orbitrap mass spectrometry. J Chromatogr A. 2014a; 1347:122-8. https://doi.org/10.1016/j.chroma.2014.04.081.

Jia W, Chu X, Ling Y, Huang J, Chang J. Multi-mycotoxin analysis in dairy products by liquid chromatography coupled to quadrupole orbitrap mass spectrometry. J Chromatogr A. 2014b;1345:107-14. https://doi.org/10.1016/j. chroma.2014.04.021

Jia W, Chu XG, Chang J, Wang PG, Chen Y, Zhang F. High-throughput untargeted screening of veterinary drug residues and metabolites in tilapia using high resolution orbitrap mass spectrometry. Anal Chim Acta. 2017;957:29-39. https://doi.org/10.1016/j.aca.2016.12.038.

Jia W, Shi L, Chu XG. Untargeted screening of sulfonamides and their metabolites in salmon using liquid chromatography coupled to quadrupole Orbitrap mass spectrometry. Food Chem. 2018a;239:427-33. https://doi.org/10.1016/j. foodchem.2017.06.143.

Jia W, Shi L, Chu XG, Chang J, Chen Y, Zhang F. A strategy for untargeted screening of macrolides and metabolites in bass by liquid chromatography coupled to quadrupole orbitrap mass spectrometry. Food Chem. 2018b;262: 110-7. https://doi.org/10.1016/j.foodchem.2018.04.090.
Junza A, Amatya R, Barrón D, Barbosa J. Comparative study of the LC-MS/MS and UPLC-MS/MS for the multi-residue analysis of quinolones, penicillins and cephalosporins in cow milk, and validation according to the regulation 2002/ 657/EC. J Chromatogr B Analyt Technol Biomed Life Sci. 2011;879(25):260110. https://doi.org/10.1016/j.jchromb.2011.07.018.

Kaufmann A, Widmer M. Quantitative analysis of polypeptide antibiotic residues in a variety of food matrices by liquid chromatography coupled to tandem mass spectrometry. Anal Chim Acta. 2013;797:81-8. https://doi.org/10.1016/j.a са.2013.08.032.

Kazakova J, Fernández-Torres R, Ramos-Payán M, Bello-Lopez MA. Multiresidue determination of 21 pharmaceuticals in crayfish (Procambarus clarkii) using enzymatic microwave-assisted liquid extraction and ultrahigh-performance liquid chromatography-triple quadrupole mass spectrometry analysis. J Pharm Biomed Anal. 2018;160:144-51. https://doi.org/10.1016/j.jpba.2018.07.057.

Kim CY, Ryu HD, Chung EG. Determination of 18 veterinary antibiotics in environmental water using high-performance liquid chromatography-qorbitrap combined with on-line solid-phase extraction. J Chromatogr B. 2018. 1084:158-65. https://doi.org/10.1016/j.jchromb.2018.03.038.

Li J, Ren XL, Diao YY, Chen Y, Wang QL, Jin WT, et al. Multiclass analysis of 25 veterinary drugs in milk by ultra-high performance liquid chromatographytandem mass spectrometry. Food Chem. 2018;257:259-64. https://doi.org/1 0.1016/j.foodchem.2018.02.144.

Li N, Ho KW, Ying GG, Deng WJ. Veterinary antibiotics in food, drinking water, and the urine of preschool children in Hong Kong. Environ Int. 2017; 108(April):246-52. https://doi.org/10.1016/j.envint.2017.08.014.

Li SJ, Ju HY, Zhang JQ, Chen P, Ji MC, Ren JH, et al. Occurrence and distribution of selected antibiotics in the surface waters and ecological risk assessment based on the theory of natural disaster. Environ Sci Poll Res. 2019;26(27): 28384-00. https://doi.org/10.1007/s11356-019-06060-7.

Li Y, Zhou G, Peng Y, Tu PF, Li XB. Screening and identification of three typical phenylethanoid glycosides metabolites from Cistanches Herba by human intestinal bacteria using UPLC/Q-TOF-MS. J Pharm Biomed Anal. 2016;118: 167-76. https://doi.org/10.1016/j.jpba.2015.10.038.

Liu L, Aljathelah NM, Hassan H, Leitão A, Bayen S. Development of a liquid chromatography-quadrupole-time-of-flight-mass spectrometry based method for the targeted and suspect screening of contaminants in the pearl oyster Pinctada imbricata radiate. Environ Pollut. 2019;253:841-9. https://doi.org/1 0.1016/j.envpol.2019.07.047.

Liu Y, Zhu K, Wang J, Huang X, Wang GL, Li CY, et al. Simultaneous detection and comparative pharmacokinetics of amoxicillin, clavulanic acid and prednisolone in cows' milk by UPLC-MS/MS. J Chromatogr B. 2016;1008:7480. https://doi.org/10.1016/j.jchromb.2015.11.031.

López-García M, Romero-González R, Frenich AG. Determination of rodenticides and related metabolites in rabbit liver and biological matrices by liquid chromatography coupled to Orbitrap high resolution mass spectrometry. J Pharm Biomed Anal. 2017;137:235-42. https://doi.org/10.1016/j.jpba.2017.01.043.

Moreno-González D, Hamed AM, Gilbert-López B, Gámiz-Gracia L, GarcíaCampaña AM. Evaluation of a multiresidue capillary electrophoresisquadrupole-time-of-flight mass spectrometry method for the determination of antibiotics in milk samples. J Chromatogr A. 2017;1510:100-7. https://doi. org/10.1016/j.chroma.2017.06.055.

Oyedeji AO, Msagati TAM, Williams AB, Benson NU. Determination of antibiotic residues in frozen poultry by a solid-phase dispersion method using liquid chromatography-triple quadrupole mass spectrometry. Toxicol Rep. 2019;6: 951-6. https://doi.org/10.1016/.toxrep.2019.09.005.

Paepe ED, Meulebroek LV, Rombouts C, Huysman S, Verplanken K, Lapauw B, et al. A validated multi-matrix platform for metabolomic fingerprinting of human urine, feces and plasma using ultra-high performance liquidchromatography coupled to hybrid orbitrap high-resolution mass spectrometry. Anal Chim Acta. 2018;1033:108-18. https://doi.org/10.1016/j.a ca.2018.06.065.

Paepe ED, Wauters J, Borght MVD, Claes J, Huysman S, Croubels S, et al. Ultrahigh-performance liquid chromatography coupled to quadrupole orbitrap high-resolution mass spectrometry for multi-residue screening of pesticides, (veterinary) drugs and mycotoxins in edible insects. Food Chem. 2019;293: 187-96. https://doi.org/10.1016/j.foodchem.2019.04.082.

Pan L, Lv B, Jiang XQ, Wang T, Ma XH, Chang NW, et al. Identification of NF-KB inhibitors following Shenfu injection and bioactivity-integrated UPLC/Q-TOFMS and screening for related anti-inflammatory targets in vitro and in silico. $J$ Ethnopharmacol. 2016;194(February):658-67. https://doi.org/10.1016/j.jep.201 6.10 .052 . 
Reinholds I, Pugajeva I, Bartkevičs V. Comparison of tandem quadrupole mass spectrometry and orbitrap high resolution mass spectrometry for analysis of pharmaceutical residues in biota samples. Mat Sci Appl Chem. 2016;33(1):510. https://doi.org/10.1515/msac-2016-0001.

Rusko J, Jansons M, Pugajeva I, Zacs D, Bartkevics V. Development and optimization of confirmatory liquid chromatography_Orbitrap mass spectrometry method for the determination of 17 anticoccidials in poultry and eggs. J Pharm Biomed Anal. 2019;1645:402-12. https://doi.org/10.1016/j. jpba.2018.10.056

Saito-Shida S, Hamasaka T, Nemoto S, Akiyama H. Multiresidue determination of pesticides in tea by liquid chromatography-high-resolution mass spectrometry: comparison between Orbitrap and time-of-flight mass analyzers. Food Chem. 2018;256:140-8. https://doi.org/10.1016/j.foodchem.2 018.02.123.

Sanli S, Palabiyik IM, Sanli N, Guzel-Seydim ZB, Alsancak G. Optimization of the experimental conditions for macrolide antibiotics in high performance liquid chromatography by using response surface methodology and determination of tylosin in milk samples. J Anal Chem. 2011;66(9):838-47. https://doi.org/1 $0.1134 /$ s1061934811090152.

Serra-Compte A, Álvarez-Muñoz D, Rodríguez-Mozaz S, Barceló D. Multi-residue method for the determination of antibiotics and some of their metabolites in seafood. Food Chem Toxicol. 2017;104:3-13. https://doi.org/10.1016/j.fct.2 016.11 .031

Socas-Rodríquez B, Herrera-Herrera AV, Hernández-Borges J, Rodríquez-Delgado MÁ. Multiresidue determination of estrogens in different dairy products by ultra-high-performance liquid chromatography triple quadrupole mass spectrometry. J Chromatogr A. 2017;1496:58-67. https://doi.org/10.1016/j. chroma.2017.03.034.

Tran N, Chen H, Do TV, Reinhard M, Ngo HH, He YL, et al. Simultaneous analysis of multiple classes of antimicrobials in environmental water samples using SPE coupled with UHPLC-ESI-MS/MS and isotope dilution. Talanta. 2016;159: 163-73. https://doi.org/10.1016/j.talanta.2016.06.006.

Weng R, Lou ST, Pang X, Song Y, Su X, Xiao ZY, et al. Multi-residue analysis of 126 pesticides in chicken muscle by ultra-high-performance liquid chromatography coupled to quadrupole time-of-flight mass spectrometry. Food Chem. 2020;309: 125503. https://doi.org/10.1016/j.foodchem.2019.125503.

Zhang D, Park JA, Kim SK, Cho SH, Jeong D, Cho SM, et al. Simultaneous detection of flumethasone, dl-methylephedrine, and 2-hydroxy-4,6dimethylpyrimidine in porcine muscle and pasteurized cow milk using liquid chromatography coupled with triple-quadrupole mass spectrometry. J Chromatogr B. 2016;1012-1013:8-16. https://doi.org/10.1016/j.jchromb.2016. 01.011

Zhang YQ, Li X, Liu XM, Zhang JJ, Cao YZ, Shi ZH, et al. Multi-class, multi-residue analysis of trace veterinary drugs in milk by rapid screening and quantification using ultra-performance liquid chromatography-quadrupole time-of-flight mass spectrometry. J Dairy Sci. 2015;98(12):8433-44. https://doi. org/10.3168/jds.2015-9826

Zhao F, Gao X, Tang ZX, Luo X, Wu MM, Xu JC, et al. Development of a simple multi-residue determination method of 80 veterinary drugs in Oplegnathus punctatus by liquid chromatography coupled to quadrupole Orbitrap mass spectrometry. J Chromatogr B. 2017;1065-1066:20-8. https://doi.org/10.1016/ j.jchromb.2017.09.013.

Zorraquino MA, Althaus RL, Roca M, Molina MP. Heat treatment effects on the antimicrobial activity of macrolide and lincosamide antibiotics in milk. J Food Prot. 2011;74(2):311-5. https://doi.org/10.4315/0362-028X.JFP-10-297.

\section{Publisher's Note}

Springer Nature remains neutral with regard to jurisdictional claims in published maps and institutional affiliations.

\section{Submit your manuscript to a SpringerOpen ${ }^{\circ}$ journal and benefit from:}

- Convenient online submission

- Rigorous peer review

- Open access: articles freely available online

High visibility within the field

- Retaining the copyright to your article

Submit your next manuscript at $\boldsymbol{\nabla}$ springeropen.com 